\title{
(EBSIS) ELECTRONIC BLOOD STOCK INFORMATION SYSTEM SEBAGAI PUSAT INFORMASI STOCK DARAH PADA UNIT TRANSFUSI DARAH (UTD) KABUPATEN SERANG
}

\author{
Akip Suhendar ${ }^{1}$, Siswanto ${ }^{2,}$ Riani Dwi Nurhamzah ${ }^{3}$ \\ ${ }^{1}$ Program studi informatika Fakultas Teknologi Informasi Universitas Serang Raya \\ ${ }^{2}$ Program studi Rekayasa sistem komputer Fakultas Teknologi Informasi Universitas Serang Raya \\ ${ }^{3}$ Program studi Sistem Informasi Fakultas Teknologi Informasi Universitas Serang Raya \\ Jln. Raya Cilegon Serang - Drangong Kota Serang
}

email: ${ }^{1}$ akip.suhendar@gmail.com, ${ }^{2}$ fitrakbar@gmail.com, ${ }^{3}$ rianinurhamzah23@gmail.com

\begin{abstract}
ABSTRAK
Smart City merupakan sebuah konsep kota cerdas yang dapat membantu masyarakat mengelola sumber daya yang ada dengan effisien dan memberikan informasi yang tepat kepada masyarakat atau lembaga dalam melakukan kegiatannya. Konsep Smart City yang menggunakan pemanfaatan teknologi sebagai tujuan utamanya dianggap dapat membantu pemerintah untuk memberikan sebuah layanan khusunya layanan kesehatan yang saat ini menjadi kebutuhan penting bagi masyarakat. UTD (Unit Tranfusi Darah) adalah instansi yang mengelola transfusi dan donor darah di seluruh indonesia. UTD PMI berperan penting dalam pengelolaan stok darah di kabupaten Serang. Selain itu UTD PMI juga memiliki peran penting yaitu melaksanakan kegiatan donor darah masal, dan acara sosialisasi kesehatan lainnya. Dengan dirancang nya Aplikasi Electronic Blood Stock Information System (EBSIS) berbasis web maka akan membantu masyarakat dalam memperoleh informasi ketersediaan stok darah secara real time.
\end{abstract}

Kata Kunci : Aplikasi, Ebsis, Smart City, UTD, Web.

\section{Pendahuluan}

Smart City merupakan sebuah konsep kota cerdas yang dapat membantu masyarakat mengelola sumber daya yang ada dengan effisien dan memberikan informasi yang tepat kepada masyarakat atau lembaga dalam melakukan kegiatannya atau pun mengantisipasi kejadian yang tak terduga sebelumnya (Pratama,2014). Kota Serang yang berada di Provinsi Banten Indonesia adalah wilayah baru hasil pemekaran, Kabupaten Serang Provinsi Banten. Sebagai ibukota provinsi, kehadirannya adalah sebuah konsekuensi logis dari keberadaan
Provinsi Banten. Konsep smart city dianggap sebagai salah sebuah performansi yang baik bagi sebuah kota, yang didukung oleh kombinasi yang pintar (smart) dari segala aktifitas, kajian, penemuan serta kesadaran dari masyarakat kota tersebut (Griffinger,2014). Karena smart city mampu memberikan dampak positif bagi pemerintah, kehidupan sosial masyarakat, kualitas hidup, dan transortasi, persaingan yang sehat dalam segala bidang dengan memanfaatkan teknologi dan komunikasi. Konsep Smart City yang menggunakan pemanfaatan teknologi sebagai tujuan utamanya dapat 
membantu pemerintah untuk memberikan sebuah layanan khusunya layanan kesehatan yang saat ini menjadi kebutuhan terpenting bagi masyarakat.

UTD PMI kabupaten Serang adalah instansi yang melayani donor darah, serta menyediakan stok darah bagi warga kota atau kabupaten Serang. Sebagai instansi yang menyediakan donor darah. UTD harus selalu siaga dalam pemberian pelayanan kesehatan kepada warga maupun rumah sakit yang membutuhkan stok darah. Selama proses pendistribusian stok darah kepada masyarakat maupun rumah sakit, pihak pasien harus mencari stok darah langsung ke UTD PMI Serang, jika banyak yang meminta darah, maka keluarga pasien harus mengantri dalam mencari stok darah pada bank darah . Jika stok darah habis, keluarga pasien harus mencari pendonor untuk mendonorkan darahnya, akibatnya pihak keluarga kesulitan mencari pendonor. UTD PMI juga memiliki peran penting lainnya yaitu melaksanakan kegiatan-kegiatan penunjang penambahan stok darah. Karena, jika tidak dilakukan kegiatankegiatan diluar seperti donor darah masal, dan acara sosialisasi kesehatan lainnya. Maka stok darah pada UTD PMI tidak akan bertahan lama mengingat volume permintaan stok darah yang lebih banyak dibanding pemasukkan stok darah. Akan tetapi kegiatan donor masal ini masih terdapat kekurangan karena informasi sosialisasi kegiatan donor masal yang kurang tersampaikan dengan baik kepada masyarakat.
Untuk menyelesaikan permasalahan yang telah dijabarkan diatas maka konsep smart city sangat dibutuhkan khususnya dalam mengembangkan sebuah aplikasi berbasis web yang dapat membantu UTD PMI Kabupaten Serang dalam memberikan informasi persediaan darah lebih cepat, efisien aman dan terpecaya untuk keperluan masyakat. Aplikasi yang di buat nantinya diharapkan dapat memenuhi segala kebutuhan informasi real-time mengenai ketersedian stok darah di UTD PMI Kabupaten Serang dimana informasi tersebut akan ter-update setiap ada pengurangan atau penambahan stok darah. Aplikasi ini juga dapat mengirimkan jadwal donor darah kepada pendonor. Disamping itu, Aplikasi ini juga menghadirkan fitur seperti cara memesan darah di UTD PMI Kabupaten bagi beberapa Rumah Sakit di Kota Serang.

\subsection{Identifikasi Masalah}

Berdasarkan latar belakang diatas, dapat di identifikasikan permasalahan yang terjadi yaitu :

1. Tidak tersedianya informasi realtime mengenai ketersediaan stok darah.

2. Tidak tersedianya media untuk melakukan pemesanan darah bagi rumah sakit kepada utd.

3. Tidak tersedianya media penyebarluasan informasi jadwal donor darah untuk para pendonor 


\subsection{Tujuan Penelitian}

1. Tersedianya informasi realtime stok darah di UTD dimana informasi tersebut akan terupdate setiap ada pengurangan serta penambahan darah.

2. Tersedianya media untuk melakukan pemesanan darah bagi beberapa rumah sakit untuk resipien yang membutuhkan darah.

3. Tersedianya media penyebarluasan informasi jadwal donor darah kepada masyarakat.

\section{Tinjauan Pustaka}

Adapun beberapa teori penunjang yang dibutuhkan dalam penelitian ini sebagai berikut :

\subsection{Aplikasi}

Aplikasi adalah suatu subkelas perangkat lunak komputer yang memanfaatkan kemampuan komputer langsung untuk melakukan suatu tugas yang diinginkan pengguna. Biasanya dibandingkan dengan perangkat lunak sistem yang mengintegrasikan berbagai kemampuan komputer, tapi tidak secara langsung menerapkan kemampuan tersebut untuk mengerjakan suatu tugas yang menguntungkan pengguna (Nazrudin Safaat, 2012).

\subsection{Bank Darah}

Bank darah adalah proses yang terjadi di laboratorium untuk memastikan bahwa darah atau produk darah yang disumbangkan adalah aman sebelum digunakan untuk transfusi darah atau prosedur medis lainnya (http://kamuskesehatan.com, 2013).

\subsection{Smart City}

Smart city atau secara harfiah berarti kota pintar, merupakan suatu konsep pengembangan, penerapan, dan implementasi teknologi yang diterapkan disuatu daerah sebagai sebuah interaksi yang kompleks di antara berbagai sistem yang ada di dalamnya (Pratama, 2014). Tujuan dari pendekatan smart city untuk mencapai informasi dan pengelolaan kota yang terintegrasi. Integrasi ini dapat melalui manajemen jaringan digital geografi perkotaan, sumber daya, lingkungan, ekonomi, sosial dan lainnya.

IBM membagi smart city menjadi enam jenis. Keenam jenis pembagian smart city tersebut meliputi smart economy, smart mobility, smart governance, smart people, smart living, dan smart environment. (Pratama, 2014).

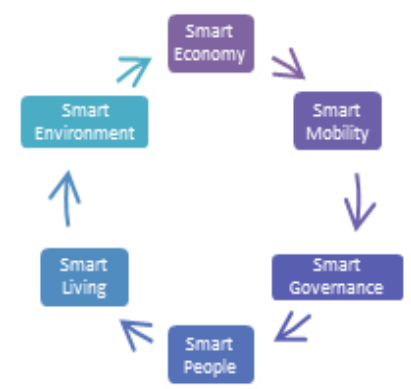

Gambar Bagian-bagian Smary City menurut IBM 


\subsection{PHP}

PHP memiliki kepanjangan Hypertext Preprocessor, merupakan suatu bahasa pemrograman yang difungsikan untuk membangun suatu website dinamis. PHP menyatu dengan kode HTML, maksudnya adalah beda kondisi. HTML digunakan sebagai pembangun atau pondasi kerangka layout web, sedangkan $P H P$ difungsikan sebagai prosesnya sehingga dengan adanya PHP tersebut sebuah web akan sangat mudah di-maintenance.

PHP berjalan pada sisi server sehingga $P H P$ disebut juga sebagai bahasa Server Side Scripting yang artinya bahwa dalam setiap/untuk menjalankan $\quad P H P, \quad$ wajib membutuhkan web server dalam menjalankannya.

PHP bersifat open source sehingga dapat dipakai secara gratis dan mampu lintas platform yaitu dapat berjalan pada sistem operasi Windows maupun Linux. PHP juga dibangun sebagai modul pada web server apache dan sebagai binary yang dapat berjalan sebagai $C G I$.

\section{Perancangan Sistem}

\subsection{Metode Pengumpulan Data}

Metode pengumpulan data yang digunakan dalam penelitian ini adalah sebagai berikut:

\section{Studi Pustaka}

Pada penelitian ini dilakukan studi komprehensif dengan membaca dan mempelajari buku-buku, jurnal, serta browsing data-data diinternet yang menjadi acuan dalam penelitian dan penulisan laporan skripsi ini.

\section{Survey Lapangan}

Suatu metode untuk memperoleh data langsung dengan cara-cara melakukan pengamatan, pengukuran, dan pencatatan terhadap data-data yang diperlukan sesuai dengan tujuan survei.

\section{Wawancara}

Merupakan tindak lanjut dari survey lapangan dengan melakukan tanya jawab dengan Kepala dan staff UTD PMI Kab Serang.

\section{Kuesioner}

Kuesioner berisi daftar pertanyaan yang diberikan kepada 15 responden, yang terdiri dari masyarakat, pendonor, dan keluarga resipien untuk mendapatkan validasi data yang ingin dibuktikan.

\subsection{Metode Pengembangan Sistem}

Metode yang digunakan yaitu menggunakan model siklus pengembangan perangkat lunak waterfall, yaitu sebuah model proses pengembangan perangkat lunak yang setiap tahapannya digambarkan mengalir ke bawah. Beberapa tahap dilakukan sebagai berikut :

\section{Analisa Kebutuhan}

Tahapan ini dilakukan untuk mengelompokkan dan menganalisa semua data dan prosedur yang ada pada UTD PMI Serang dalam melakukan pencarian stok darah. Kemudian dilakukan analisa secara fungsional sistem yang akan dirancang. 


\section{Perancangan Sistem}

Dalam tahapan ini akan membuat rancangan database dan rancangan user interface yang meliputi interface untuk petugas pada web server dan interface untuk pengguna client pada aplikasi bank darah di web.

\section{Pembutatan Program}

Rancangan yang sudah dibuat sebelumnya ditranslasikan dalam bentuk kode-kode program agar aplikasi tersebut dapat dijalankan pada perangkat yang dispesifikasikan. Rancangan web server ditranslasikan dalam bahasa pemrograman php YII framework Rancangan database di implementasikan ke dalam $D B M S M Y S Q L$.

\section{Testing}

Setelah sistem ini di selesai dibuat, maka dilakukan pengujian sistem menggunakan metodologi blackbox untuk mecari kesalahan atau bug sehingga dapat diperbaiki kemudian dilakuan terhadap fokus permasalahan penelitian, apakah sudah sesuai seperti yang diinginkan.

\section{Implementasi}

Setelah sistem selesai diuji maka selanjutnya akan diimpelementasikan di UTD PMI Kabupaten Serang.

\subsection{Use Case Diagram}

Diagram use case merupakan pemodelan untuk kelakukan (behavior) sistem informasi yang akan dibuat. Use case mendeskripsikan sebuah interaksi antara satu atau lebih aktor dengan sistem informasi yang akan dibuat. Adapun Use case diagram pada rancangan sistem sebagai berikut :

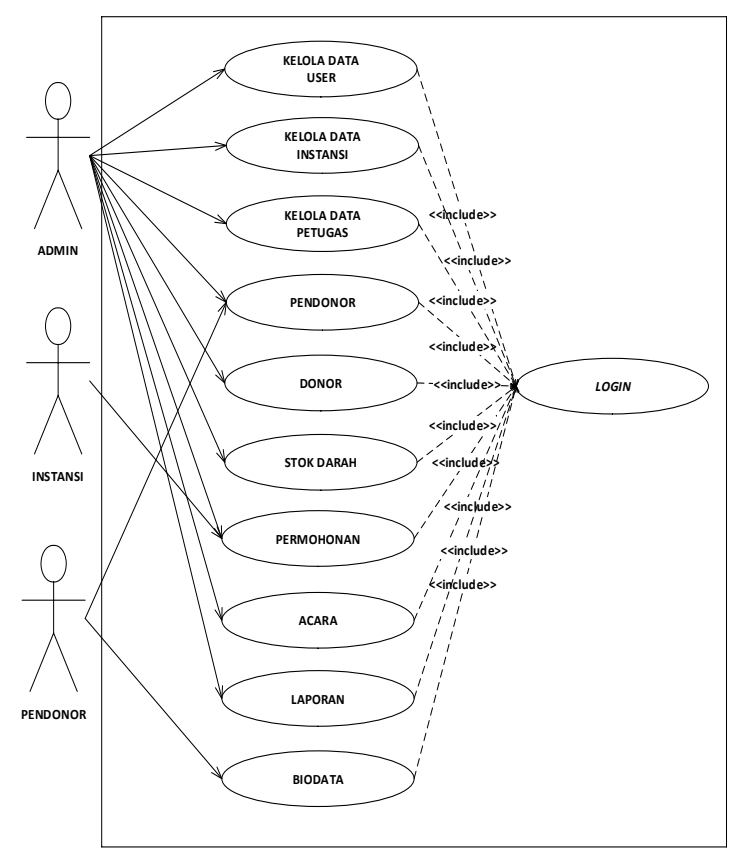

\section{Hasil Dan Pembahasan}

Dalam pembahasan ini dideskripsikan secara detail, tampilan menu dan halaman yang terdapat didalam aplikasi Smart-Blood dalam bentuk screenshoot aplikasi :

\section{Halaman Login}

Sebelum masuk ke halaman menu, user diharuskan melakukan login terlebih dahulu agar bisa mengakses menu yang ada pada Aplikasi Smart-Blood dengan memasukkan username dan password terdaftar didalam basisdata sistem informasi bank data. Pengguna meng-input data sesuai level user yang digunakan. 


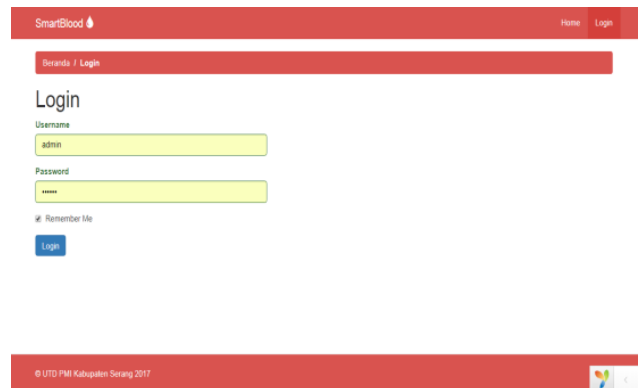

\section{Tampilan Menu User}

Menu ini menampilkan tabel-tabel yang berisikan data informasi mengenai siapa saja user yang telah terdaftar pada database sistem. Pada menu user ini dilengkapi tomboltombol fungsi pengolahan data yang terdiri dari tambah, lihat, edit dan hapus.

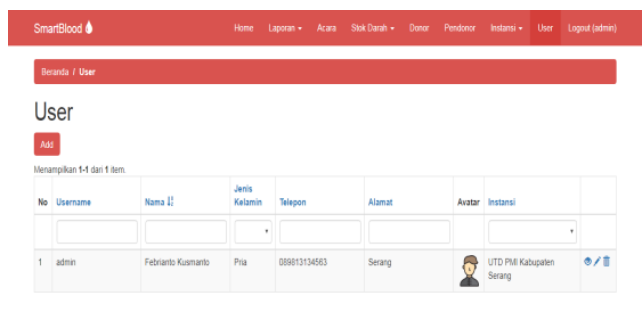

\section{Tampilan Menu Instansi}

Pada menu ini menampilkan data informasi mengenai instansi terkait yang terlibat dalam sistem. Menu ini hanya bisa diakses oleh admin saja, karena dalam hal ini admin adalah pihak yang memiliki akses untuk melakukan perubahan dan penambahan daftar instansi yang terlibat. Pada menu instansi ini dilengkapi tomboltombol fungsi pengolahan data yang terdiri dari tambah, lihat, edit dan hapus.

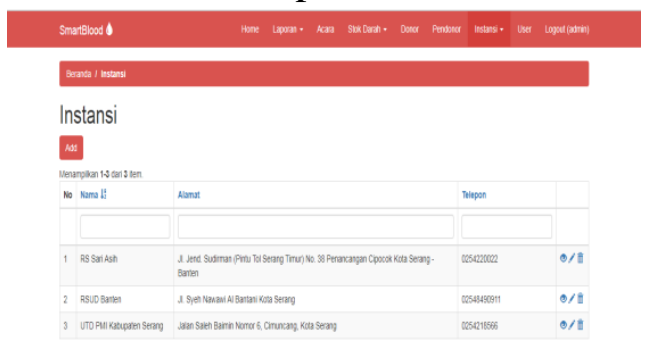

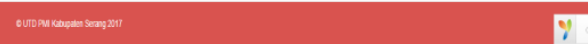

\section{Tampilan Menu Petugas Instansi}

Pada menu ini menampilkan data informasi mengenai petugas instansi terkait yang terlibat dalam sistem. Menu ini hanya bisa diakses oleh admin saja, karena dalam hal ini admin adalah pihak yang memiliki akses untuk melakukan perubahan dan menambah daftar petugas instansi yang terlibat. Pada menu user ini dilengkapi tombol-tombol fungsi pengolahan data yang terdiri dari tambah, lihat, edit dan hapus.

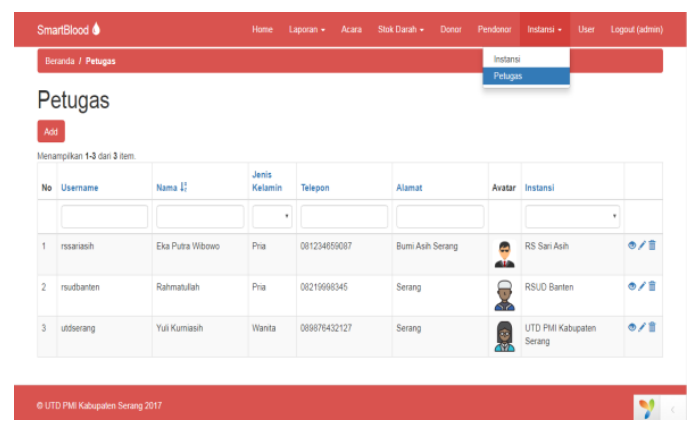

\section{Tampilan Menu Pendonor}

Halaman pendonor ini berfungsi untuk melakukan proses registrasi untuk calon pendonor. Dimana nantintya pendonor yang sudah terdaftar bisa melakukan login ke system. 
stok darah yang dimiliki UTD ke

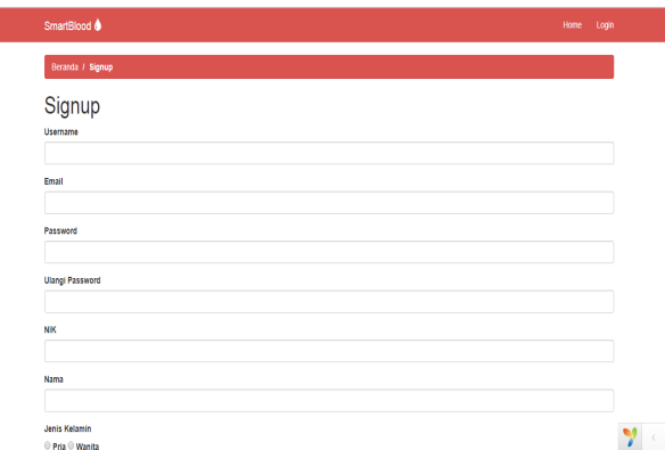

6. Tampilan Menu Donor

$\begin{array}{cr}\text { Halaman donor ini } \\ \text { menampilkan } & \text { data-data }\end{array}$

berfungsi untuk mengolah data donor. Menu ini hanya bisa di akses oleh admin saja. karena dalam hal ini admin adalah pihak yang memiliki akses untuk melakukan proses peginputan jumlah donor yang dilakukan pendonor yang terdaftar dalam sistem. Pada menu ini dilengkapi tomboltombol fungsi pengolahan data yang terdiri dari yang terdiri dari lihat, ubah dan hapus.

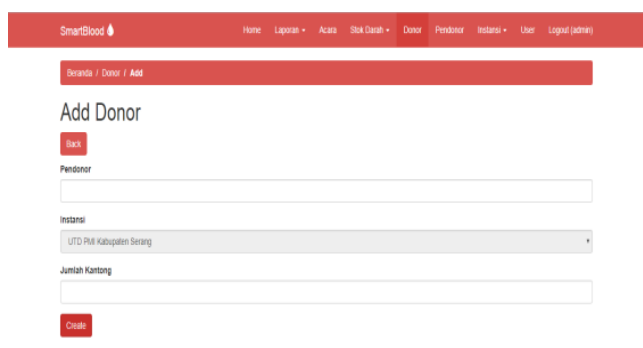

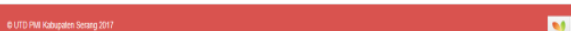

\section{Tampilan Menu Stok Darah}

Halaman stok darah ini menampilkan data stok darah. Menu ini hanya bisa di akses dan dikelola oleh admin saja. karena dalam hal ini admin adalah pihak yang memiliki akses untuk melakukan pengupdatetan jumlah
Apliaksi. Pada menu ini dilengkapi tombol-tombol fungsi pengolahan data yang terdiri dari yang terdiri dari lihat dan update. Adapun tampilan menu ini disajikan pada gambar berikut

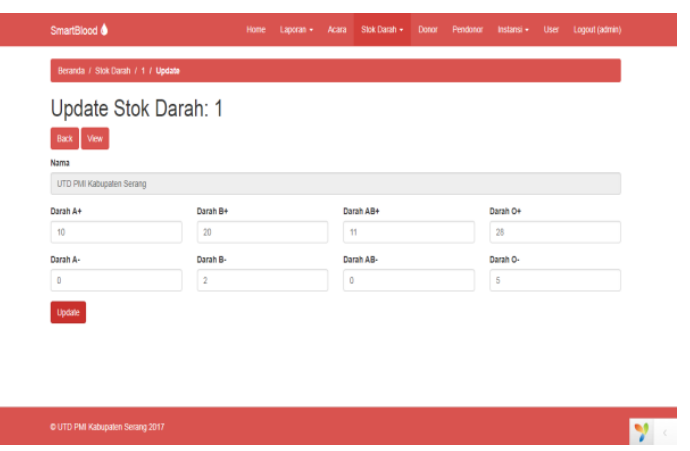

\section{Tampilan Menu Permohonan}

Halaman permohonan ini berfungsi untuk mengolah data permohonan darah bagi rumah sakit atau instansi yang terdaftar dalam sistem. Pada menu ini menampilkan tabel data permohonan darah dari rumah sakit ke pihak UTD PMI Serang. Pada form permohonan ini rumah sakit mengirim permohonan darah ke utd.

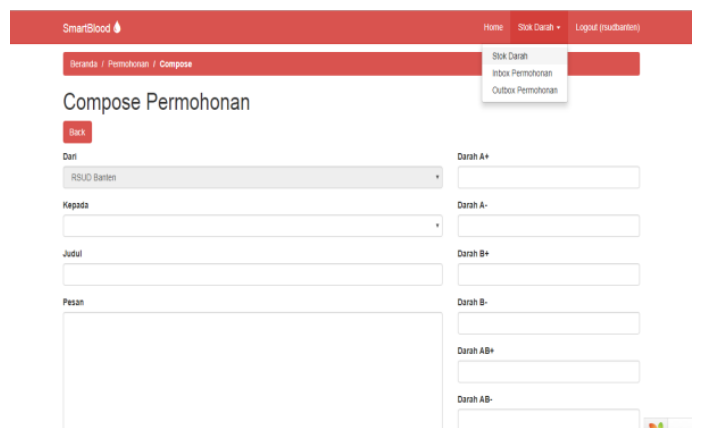

Pada tabel inbox masuk ini menampilkan tabel data permohonan darah dari rumah sakit ke pihak UTD PMI Serang. Yang untuk selanjutnya admin memberikan tanda ceklis jika tersedia, atau tanda silang jika tidak tersedia. 


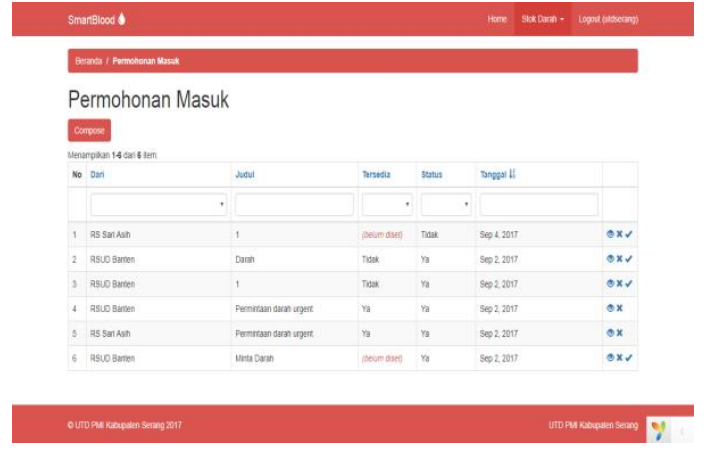

9. Tampilan Menu Acara

Pada menu ini menampilkan informasi mengenai acara donor darah. Menu ini hanya bisa diakses oleh admin saja, karena dalam hal ini admin adalah pihak yang memiliki akses untuk melakukan perubahan dan menambah acara donor. Dan dalam menu acara ini ketika admin membuat acara baru maka otomatis jadwal acara baru akan terkirim otomatis via email ke semua pendonor yang terdaftar dalam aplikasi SmartBlood. Pada menu acara ini dilengkapi tombol-tombol fungsi pengolahan data yang terdiri dari tambah, lihat, edit dan hapus.

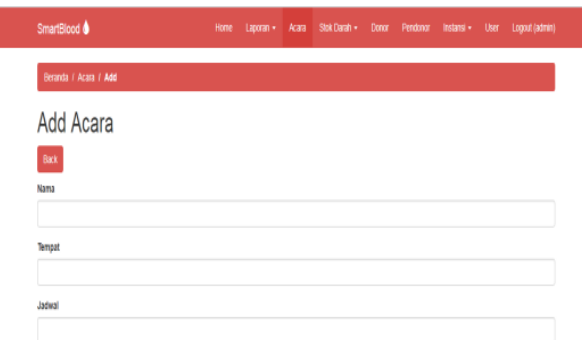

$\rightarrow$

\section{Tampilan Menu Laporan}

Pada menu ini menampilkan laporan jumlah stok darah. Menu ini hanya diperuntukan bagi admin untuk mencetak laporan stok darah yang akan diberikan kepada pimpinan. Tampilan daripada fungsi menu ini digambarkan pada gambar berikut.

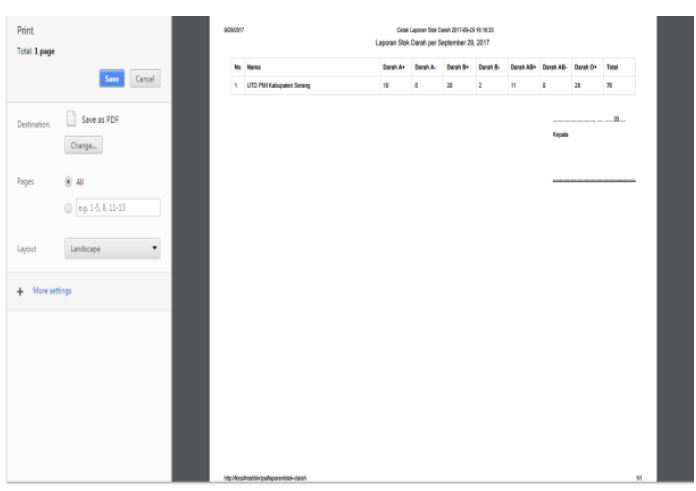

\section{Tampilan Menu Biodata}

Pada menu ini menampilkan tabel data biodata pendonor yang terdaftar didalam sistem, yang di dalamnya hanya terdapat menu untuk melihat dan mengubah data pribadi pendonor.

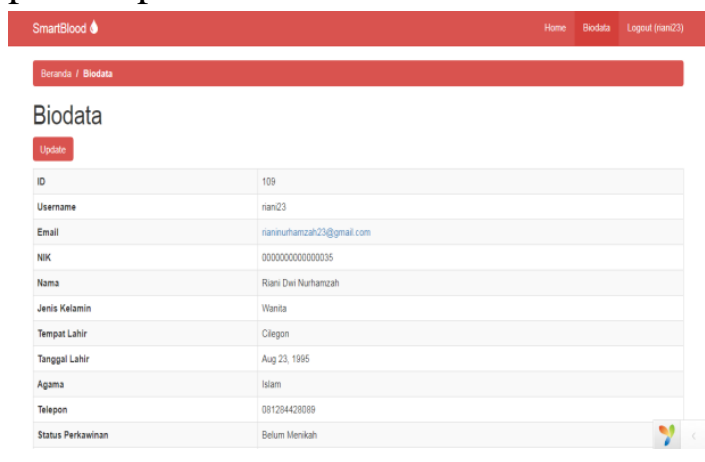

\section{Kesimpulan Dan Saran}

\subsection{Kesimpulan}

Berdasarkan hasil penelitian dan pengujian aplikasi Smart-Blood yang telah dilakukan oleh penulis maka dapat diambil beberapa kesimpulan, yaitu:

1. Aplikasi Smart-Blood dirancang dan dibuat untuk memberikan 
informasi mengenai stok darah dan acara donor darah di UTD PMI Serang dengan melalui perancangan $U M L, E R D$, Basis Data dan Antar Muka. Menggunakan bahasa pemrograman $P H P$ dan kerangka kerja PHP Yii Framework serta visual Studio Code sebagai media scripting.

2. Aplikasi Smart-Blood ini realtime memberikan update stok darah yang dimiliki dimana informasi akan ter-update setiap ada pengurangan dan penambahan darah. Serta aplikasi ini juga dapat melakukan pemesanan darah jika pasokan darah dirumah sakit berkurang atau habis kepada pihak UTD PMI Serang. Namun, hanya rumah sakit yang terdaftar saja yang dapat melakukan pemesanan darah via aplikasi.

3. Aplikasi Smart-Blood dibangun untuk memberikan informasi kepada pendonor tentang jadwal donor darah, yang berupa notifikasi email kepada pendonor jika ada acara.

\subsection{Saran}

Dalam pembangunan sistem informasi bank darah ini masih terdapat beberapa kekurangan. Oleh karena itu perlu dilakukan pengembangan dan penyempurnaan lebih lanjut. Adapun saran agar sistem ini bisa berfungsi dengan lebih optimal dan lebih menarik sebagai berikut:

1. Sistem hanya sebatas simulasi, kedepan harapannya UTD PMI Serang mampu mengimplementasi
Aplikasi Smart-Blood dengan melakukan perbaikan sistem yang telah disimulasikan agar sistem bisa di implementasikan pada UTD PMI Serang

2. Penelitian ini sedianya hanya meringankan kinerja para petugas UTD PMI Serang dalam mengelola data bank darah, tanpa meninggalkan aktifitas kerja sebelum sistem ini dibangun, karena sistem ini belum tentu bisa membantu meringankan kinerja petugas jika petugas belum siap dengan penggunaan teknologi.

3. Tampilan Interface pada aplikasi Smart-Blood masih cukup sederhana, sehingga jika ada pengembangan kedepan dari pihak UTD PMI Serang maka dapat membuat tampilan yang lebih menarik.

Demikian saran yang dapat disampaikan, semoga saran tersebut bisa dijadikan sebagai bahan masukkan yang dapat bermanfaat bagi penulis khususnya dan umumnya bagi masyarakat luas.

\section{Daftar Pustaka}

Afnillah, dan Hindarto. (2015). "Aplikasi Bank Darah di PMI Surabaya Berbasis Website dan Web". Jurnal Teknik Informatika Universitas Muhamadiyah Sidoarjo.

Binanto, Iwan. (2015). "Analisa Metode Classic Life Cycle (Waterfall) Untuk Pengembangan Perangkat Lunak Multimedia". Jurnal Teknik Informatika Universitas Sanata Dharma Yogyakarta. 
Gustaman, Rian Arie, Eka Wahyu Hidayat dan Nurul Hiron. (2016). " Sistem Informasi Pelayanan Donor Darah Berbasis Web (Studi Kasus: PMI Tasikmalaya)". Seminar Nasional Teknologi Informasi dan Multimedia STMIK AMIKOM Yogyakarta.

Hamzah. (2015). "Analisa dan Rancangan Sistem Informasi Ketersediaan Donor Darah Hidup". Jurnal Ilmiah Teknologi Informasi Terapan Vol. 1, No 2.

Haerani, D. (2016). Wujudkan Smart City Pegawai Pemkot Serang Wajib Melek Teknologi. [Online]. [17 maret 2017]

Irwanto, Djon. (2005). Perancangan Object Oriented Software dengan UML. Jakarta: Andi Publishing.

Junaidi, Deki. (2013). "Sistem Informasi Bank Darah Pada Unit Donor Darah UDD PMI Kota Dumai Berbasis Android". Skripsi. Riau: Fakultas Sains Dan Teknologi UIN SUSKA RIAU.

Pratama, I Putu Agus Eka. (2014). Smart City Beserta Cloud Computing dan Teknologi-Teknologi Pendukung lainnya. Bandung: Informatika Bandung.
Putri, Mutia Fadhila, dkk. (2016). "BShare Aplikasi Bank Darah Untuk Mempercepat Penyedian Informasi Darah Sebagai Pendukung Terciptanya Smart City". Prosiding Annual Research Seminar 2016 Vol. 2, No. 1.

Rizky, Soetam. (2011). Konsep Dasar Rekayasa Perangkat Lunak. Jakarta: Prestasi Putrakaya.

Rosita, Ratna, dkk. (2008). Pedoman

Pengelolaan Darah Rumah Sakit (BDRS). Jakarta: Depkes RI.

Sapoetra, Arif Naufan. (2015). Cara Menghitung Kuesioner Skala Likert. [Online]. [29 september 2017]

Sharive. (2014). Proyek Membangun Website dengan Yii Framework. Yogyakarta: Lokomedia.

Syahputra, Andry. (2003). Apache Web Server. Yogyakarta: Andi Offset.

Utomo, Karyo Budi. (2010). "Perancangan Sistem Informasi Bank Darah Hidup Untuk Mempercepat Penyediaan Calon Penyumbang Darah Dengan Ketepatan Yang Tinggi (Studi di PMI Kota Samarinda". Jurnal Informatika Mulawarman Vol. 5, No. 2. 